\title{
Sifat Lapangan pada Bilangan Kompleks
}

\author{
Ida Nuraida ${ }^{1, a)}$ \\ ${ }^{1}$ Prodi Pendidikan Matematika UIN Sunan Gunung Djati Bandung \\ Jl. AH. Nasution 105 Bandung, Indonesia \\ a)Email: idanuraida@uinsgd.ac.id
}

Dikirim: Maret 2017 ;Diterima: Juni 2017; Dipublikasikan: Juni 2017

\begin{abstract}
Abstrak. Dalam teori gelanggang dibahas sifat-sifat lapangan (field) pada suatu sistem bilangan. Suatu gelanggang komutatif $L$ disebut lapangan jika untuk setiap $a \in L$ dan $a \neq 0$ terdapat $a^{-1} \in L$, sehingga $a a^{-1}=a^{-1} a=1$. Diantaranya adalah sifat lapangan pada sistem bilangan kompleks. Bilangan kompleks adalah bilangan yang berbentuk $a+b i$ atau $a+i b, a$ dan $b$ bilangan real dan $i^{2}=-1$. Notasi bilangan kompleks dinyatakan dengan huruf . Dapat dibuktikan bahwa bilangan kompleks memiliki sifat-sifat lapangan yang memenuhi 10 sifat, yaitu sifat tertutup penjumlahan dan perkalian, komutatif penjumlahan dan perkalian, assosiatif penjumlahan dan perkalian, memiliki identitas penjumlahan dan perkalian, memiliki balikan (invers) penjumlahan dan balikan perkalian.
\end{abstract}

Kata Kunci : bilangan komplek, gelanggang, gelanggang komutatif, lapangan

\section{Pendahuluan}

Di dalam matematika terdapat himpunan bilangan yang disebut bilangan kompleks. Bilangan kompleks adalah himpunan bilangan terbesar. Himpunan bilangan real yang dipakai sehari-hari merupakan himpunan bagian dari himpunan bilangan kompleks. Secara umum bilangan kompleks terdiri dari dua bagian : bagian real dan bagian imajiner (khayal). Bagian khayal bercirikan hadirnya bilangan khayal $i$, yang didefinisikan sebagai $i=\sqrt{1}$.

Bilangan kompleks adalah bilangan yang berbentuk $a+b i$ atau $a+i b, a$ dan $b$ bilangan real dan $i^{2}=-1$. Notasi bilangan kompleks dinyatakan dengan huruf . Jika $z \in \quad \operatorname{dan} z=x+i y$ menyatakan sembarang bilangan 
kompleks, maka $x$ dinamakan bagian real dan $y$ bagian imajiner dari $z$. Bagian real dan bagian imaginer dari bilangan kompleks $Z$ biasanya dinyatakan dengan $\operatorname{Re}(z)$ dan $\operatorname{Im}(z)$.

Beberapa operasi hitung pada bilangan kompleks adalah

a. Bilangan kompleks $z_{1}=x_{1}+i y_{1}$ dan bilangan kompleks $z_{2}=x_{2}+$ $i y_{2}$ dikatakan sama, $z_{1}=z_{2}$, jika dan hanya jika $x_{1}=x_{2}$ dan $y_{1}=y_{2}$.

b. Untuk bilangan kompleks $z_{1}=x_{1}+$ $i y_{1}$ dan $z_{2}=x_{2}+i y_{2}$ jumlah dan hasilkali mereka berturut-turut didefinisikan sbb:

$$
\begin{gathered}
z_{1}+z_{2}=\left(x_{1}+x_{2}\right)+i\left(y_{1}+y_{2}\right) \\
z_{1} \cdot z_{2}=\left(x_{1} x_{2}-y_{1} y_{2}\right)+i\left(x_{1} y_{2}\right. \\
\left.\quad+x_{2} y_{1}\right)
\end{gathered}
$$

Notasi dari bilangan kompleks adalah . Maka dapat dituliskan sebagai = $\{z \mid z=x+i y, x \in, y \in \quad\} . \quad$ Jika $\operatorname{Im}(z)=0$ maka bilangan kompleks $z$ menjadi bilangan real $x$, sehingga bilangan real adalah keadaan khusus dari bilangan kompleks, sehingga $\subset$. Jika $\operatorname{Re}(z)=$ 0 dan $\operatorname{Im}(z) \neq 0$, maka $z$ menjadi iy dan dinamakan bilangan imajiner murni. Bilangan imajiner murni dengan $y=0$, yakni bilangan $i$, dinamakan satuan imajiner.
Selanjutnya, akan dibahas teori gelanggang sebagai dasar dalam pembahasan sifat lapangan pada bilangan kompleks. Himpunan tak hampa yang dilengkapi dengan satu atau lebih operasi disebut sistem matematika. Berikut ini disajikan sistem matematika yang dilengkapi dua operasi.

Gilbert (2000) menyatakan bahwa suatu grup adalah sistem aljabar yang sederhana karena hanya memiliki satu operasi biner. Satu tingkat yang lebih tinggi adalah gelanggang (ring). Gelanggang memiliki dua operasi yaitu operasi penjumlahan dan perkalian. Berikut definisi dari gelanggang.

Definisi 1: Himpunan $R$ disebut gelanggang jika

a. Komutatif penjumlahan, $a+b=$ $b+a, \forall a, b \in \mathrm{R}$

b. Tertutup penjumlahan, $a+b \in$ $R, \forall a, b \in R$

c. Assosiatif penjumlahan, $a+$ $(b+c)=(a+b)+c, \forall a, b, c \in R$

d. Identitas penjumlahan, $\exists 0 \in$ $R$, sedemikan sehingga $0+a=a$, $\forall a \in R$

e. Invers penjumlahan, $\forall a \in R, \exists \quad a \in$ $R$, sedemikian sehingga $a+(a)=$ 0

f. Tertutup perkalian, yaitu $a \quad b=b \quad a$ g. Sifat assosiatif, yaitu $(a b) c=a(b c)$, untuk setiap $a, b, c \in R$. 
h. Terhadap operasi $(+)$ dan $(\times)$, $(R,+, \times)$ memenuhi sifat distributif, yaitu $a(b+c)=a b+a c$ dan $(a+b) c=a c+b c$, untuk setiap $a, b, c \in R$.

Menurut Herstein (1975) Aksioma 1 s.d. 5 disebut grup abelian atau grup komutatif dengan operasi penjumlahan. Aksioma 6 dan 7 tertutup di bawah sifat assosiatif perkalian, sedangkan aksioma 8 adalah gabungan operasi penjumlahan dan perkalian.

Sifat yang lainnya yang boleh ada pada suatu gelanggang adalah elemen satuan atau elemen identitas 1 dalam gelanggang $R$, sedemikian sehingga $a \cdot 1=1 \cdot a=a$, untuk setiap $a \in R$. Selanjutnya kita mendeskripsikan gelanggang ini sebagai gelanggang dengan unsur satuan di dalamnya.

Jika dalam suatu gelanggang $R$ berlaku $a . b=b . a$, untuk setiap $a, b \in R$, maka $R$ disebut gelanggang komutatif. Muchlis (2007) menyatakan sistem matematika dengan dua operasi penjumlahan dan perkalian disebut lapangan jika $R$ membentuk gelanggang komutatif yang semua unsur tak nolnya merupakan unit.

Definisi 2: Suatu gelanggang komutatif $L$ disebut lapangan jika untuk setiap $a \in L$ dan $a \neq 0$ terdapat $a^{-1} \in L$, sehingga $a a^{-1}=a^{-1} a=1$.

Hubungan antara daerah integral dan lapangan adalah bahwa setiap lapangan adalah merupakan daerah integral. Tapi, tidak setiap daerah integral merupakan suatu lapangan.

\section{Metodologi Penelitian}

Pada penelitian ini dilakukan dengan melakukan studi literatur terhadap beberapa referensi untuk membuktikan bahwa terdapat sifat-sifat lapangan pada sistem bilangan komplek. Sifat-sifat yang dibuktikan adalah yaitu sifat tertutup penjumlahan dan perkalian, komutatif penjumlahan dan perkalian, assosiatif penjumlahan dan perkalian, memiliki identitas penjumlahan dan perkalian, memiliki balikan (invers) penjumlahan dan balikan perkalian.

\section{Hasil dan Pembahasan}

Untuk membuktikan bilangan kompleks adalah merupakan lapangan (field), akan dibuktikan terlebih bahwa bilangan kompleks merupakan gelanggang komutatif yang memiliki invers terhadap perkalian dan memenuhi sifat-sifat berikut.

Misalkan : 
Sifat Lapangan pada Bilangan Kompleks

$$
\begin{gathered}
z_{1}, z_{2}, z_{3} \in, \text { dengan } z_{1}=a_{1}+b_{1} i ; \\
z_{2}=a_{2}+b_{2} i ; z_{3}=a_{3}+b_{3} i \text { dan } \\
a_{1}, a_{2}, a_{3}, b_{1}, b_{2}, b_{3} \in .
\end{gathered}
$$

a. Komutatif terhadap penjumlahan

$$
\begin{aligned}
& z_{1}+z_{2}=\left(a_{1}+b_{1} i\right)+\left(a_{2}+b_{2} i\right) \\
& =\left(a_{1}+a_{2}\right)+\left(b_{1}+b_{2}\right) i \\
& =\left(a_{2}+a_{1}\right)+\left(b_{2}+b_{1}\right) i \\
& =\left(a_{2}+b_{2} i\right)+\left(a_{1}+b_{1} i\right) \\
& =z_{2}+z_{1} \in .
\end{aligned}
$$

b. Bilangan kompleks tertutup terhadap penjumlahan

$$
z_{1}+z_{2}=\left(a_{1}+b_{1} i\right)+\left(a_{2}+b_{2} i\right)
$$

$\in$

c. Bilangan kompleks assosiatif terhadap penjumlahan

$$
\begin{aligned}
& \left(z_{1}+z_{2}\right)+z_{3}=\left(\left(a_{1}+a_{2}\right)\right. \\
& \left.+\left(b_{1}+b_{2}\right) i\right)+\left(a_{3}+b_{3} i\right) \\
& =\left(a_{1}+a_{2}+a_{3}\right)+\left(b_{1}+b_{2}+b_{3}\right) i \\
& =\left(a_{1}+\left(a_{2}+a_{3}\right)\right)+\left(b_{1} i+\left(a_{2}\right.\right. \\
& \left.\left.\quad+a_{3}\right) i\right) \\
& =\left(a_{1}+b_{1} i\right)+\left(\left(a_{2}+a_{3}\right)\right. \\
& \left.\quad+\left(b_{2}+b_{3}\right) i\right) \\
& =z_{3}+\left(z_{2}+z_{3}\right)
\end{aligned}
$$

d. Terdapat identitas penjumlahan bilangan kompleks

Terdapat $0_{z}=0+0 i \in$, sehingga $z_{1}+0_{z}=\left(a_{1}+b_{1} i\right)+(0+0 i)=$ $\left(a_{1}+0\right)+\left(b_{1}+0\right) i=a_{1}+b_{1} i=z_{1}$, untuk setiap $z_{1} \in$

e. Bilangan kompleks memiliki invers penjumlahan
Untuk setiap $\quad z_{1}=a_{1}+b_{1} i \in$ , terdapat $\quad z_{1}=\left(a_{1}+b_{1}\right) i \in$ , sedemikian sehingga $z_{1}+\left(z_{1}\right)=$ $\left(a_{1}+b_{1} i\right)+\left(\left(a_{1}+b_{1} i\right)\right)=a_{1}+$ $b_{1} i+\left(a_{1}\right)+\left(b_{1} i\right)=\left(a_{1}+\right.$ $\left.\left(a_{1}\right)\right)+\left(b_{1} i+\left(b_{1} i\right)\right)=0+$ $\left(b_{1}+\left(b_{1}\right)\right) i=0+0 i$

f. Sifat Komutatif perkalian

$$
\begin{aligned}
& z_{1} \quad z_{2}=\left(a_{1}+b_{1} i\right)\left(a_{2}+b_{2} i\right) \\
& =a_{1} a_{2}+a_{1} b_{2} i+b_{1} a_{2} i \quad b_{1} b_{2} \\
& =a_{1} a_{2}+b_{1} a_{2} i+a_{1} b_{2} i \quad b_{1} b_{2} \\
& =a_{2}\left(a_{1}+b_{1} i\right)+b_{2} i\left(a_{1}+b_{1} i\right) \\
& =\left(a_{2}+b_{2} i\right)\left(a_{1}+b_{1} i\right) \\
& =z_{2} \quad z_{1}
\end{aligned}
$$

g. Sifat assosiatif perkalian

$$
\begin{gathered}
\left.\begin{array}{c}
\left(z_{1} \quad z_{2}\right) z_{3} \\
=\left[\left(a_{1}+b_{1} i\right)\left(a_{2}+b_{2} i\right)\right]\left(a_{3}+b_{3} i\right) \\
=\left(a_{1}+b_{1} i\right)\left(a_{2}+b_{2} i\right) a_{3} \\
\quad+\left(a_{1}+b_{1} i\right)\left(a_{2}\right. \\
\left.\quad+b_{2} i\right) b_{3} i
\end{array}\right] \\
\begin{array}{c}
\left.\left(a_{1}+b_{1} i\right)\left(a_{2} a_{3}+b_{2} a_{3} i\right)\right] \\
\quad+\left[( a _ { 1 } + b _ { 1 } i ) \left(a_{2} b_{3} i\right.\right.
\end{array} \\
\left.\left.\quad b_{2} b_{3}\right)\right] \\
=\left(a_{1}+b_{1} i\right)\left[\left(a_{2} a_{3}+b_{2} a_{3} i\right)\right. \\
\left.\quad+\left(a_{2} b_{3} i \quad b_{2} b_{3}\right)\right]
\end{gathered}
$$

h. Identitas perkalian

Terdapat $z_{1} \in$, dengan $z_{1} \neq 0$, yang memenuhi $z_{1} \quad z_{2}=z_{2} \quad z_{1}=z_{2}$ 


$$
\begin{gathered}
\begin{aligned}
& z_{1} \quad z_{2}=\left(a_{1}+b_{1} i\right)\left(a_{2}+b_{2} i\right) \\
&= a_{2}+b_{2} i
\end{aligned} \\
a_{1} a_{2} \quad b_{1} b_{2}+\left(a_{1} b_{2}+b_{1} a_{2}\right) i \\
=a_{2}+b_{2} i
\end{gathered}
$$

Dengan melakukan substitusi $b_{1}=$ 0 diperoleh $a_{1}=1$, sehingga $z_{1}=1+$ $0 i$ adalah elemen identitas dari sistem bilangan komplek .

i. Sifat Distributif

Terhadap operasi $(+)$ dan $(\times),(,+, \times)$ memenuhi sifat distributive

$$
\begin{gathered}
z_{1}\left(z_{2}+z_{3}\right)=\left(a_{1}+b_{1} i\right)\left[\left(a_{2}+b_{2} i\right)\right. \\
\left.+\left(a_{3}+b_{3} i\right)\right] \\
=\left(a_{1}+b_{1} i\right)\left(a_{2}+a_{3}+b_{2} i+b_{3} i\right) \\
=a_{1} a_{2}+a_{1} a_{3}+a_{1} b_{2} i+a_{1} b_{3} i \\
+b_{1} a_{2} i+b_{1} a_{3} i \\
b_{1} b_{2} \quad b_{1} b_{3} \\
=\left(a_{1} a_{2}+a_{1} b_{2} i+b_{1} a_{2} i \quad b_{1} b_{2}\right) \\
+\left(a_{1} a_{3}+a_{1} b_{3} i\right. \\
\left.+b_{1} a_{3} i \quad b_{1} b_{3}\right) \\
=\left[a_{1}\left(a_{2}+b_{2} i\right)+b_{1} i\left(a_{2}+b_{2} i\right)\right] \\
+\left[a_{1}\left(a_{3}+b_{3} i\right)\right. \\
\left.+b_{1} i\left(a_{3}+b_{3} i\right)\right] \\
=\left(a_{1}+b_{2} i\right)\left(a_{2}+b_{2} i\right) \\
+\left(a_{1}+b_{2} i\right)\left(a_{3}\right. \\
\left.+b_{3} i\right)
\end{gathered}
$$

$$
=z_{1} z_{2}+z_{1} z_{3}
$$

j. Memiliki Invers terhadap Perkalian Untuk setiap $z_{2} \in$, terdapat $z_{1} \in$ sedemikian sehingga $z_{1} \quad z_{2}=1$

$$
\begin{aligned}
& z_{1} \quad z_{2}=1 \\
& \left(a_{1}+b_{1} i\right)\left(a_{2}+b_{2} i\right)=1 \\
& \left(\begin{array}{ll}
a_{1} a_{2} & b_{1} b_{2}
\end{array}\right)+\left(b_{1} a_{2}\right. \\
& \left.+a_{1} b_{2}\right) i=1+0 i \\
& a_{1} a_{2} \quad b_{1} b_{2}=1 \mid \times b_{2} \\
& a_{1} b_{2}+b_{1} a_{2}=0 \mid \times a_{2} \\
& a_{1} a_{2} b_{2} \quad b_{1} b_{2}^{2}=b_{2} \\
& \underline{a_{1} a_{2} b_{2} \quad b_{1} a_{2}^{2}=0}- \\
& b_{1} b_{2}^{2}+b_{1} a_{2}^{2}=b_{2} \\
& b_{1}\left(\begin{array}{ll}
b_{2}^{2} & a_{2}^{2}
\end{array}\right)=b_{2} \\
& b_{1}=\frac{b_{2}}{b_{2}^{2}+a_{2}^{2}}
\end{aligned}
$$

Selanjutnya dilakukan substitusi untuk mendapatkan $a_{1}$

$$
\begin{aligned}
& a_{1} a_{2} \quad b_{1} b_{2}=1 \\
& a_{1} a_{2}+\frac{b_{2}^{2}}{b_{2}^{2}+a_{2}^{2}}=1 \\
& a_{1} a_{2}=1 \quad \frac{b_{2}^{2}}{b_{2}^{2}+a_{2}^{2}} \\
& a_{1} a_{2}=\frac{b_{2}^{2}+a_{2}^{2}}{b_{2}^{2}+a_{2}^{2}} \frac{b_{2}^{2}}{b_{2}^{2}+a_{2}^{2}} \\
& \quad=\frac{a_{2}^{2}}{b_{2}^{2}+a_{2}^{2}} \\
& a_{1}=\frac{a_{2}}{b_{2}^{2}+a_{2}^{2}}
\end{aligned}
$$

Diperoleh invers $z_{2}$ adalah $z_{1}=$ $\frac{a_{2}}{b_{2}^{2}+a_{2}^{2}} \quad \frac{b_{2}}{b_{2}^{2}+a_{2}^{2}} i \in$. 
Dari sifat a s.d. j yang telah dibuktikan, terbukti bahwa sistem bilangan kompleks merupakan suatu field (lapangan).

\section{Simpulan dan Saran}

Dalam pembahasan ini disimpulkan bahwa sistem bilangan kompleks dengan operasi penjumlahan dan perkalian memenuhi sifat-sifat yang dimiliki oleh lapangan (field), sifat-sifat yang dibuktikan adalah yaitu sifat tertutup penjumlahan dan perkalian, komutatif penjumlahan dan perkalian, assosiatif penjumlahan dan perkalian, memiliki identitas penjumlahan dan perkalian, memiliki balikan (invers) penjumlahan dan balikan perkalian.

Saran dalam penelitian ini adalah adanya studi lanjutan tentang sifat-sifat dari bilangan kompleks dan juga kajian terhadap sistem bilangan-bilangan lainnya.

\section{Daftar Pustaka}

Herstein, I.N. 1975. Topics in Algebra. $2^{\text {nd }}$ Ed. New York : John Wiley and Sons. Gilbert, Jimmie \& Gilbert, Linda. 2000. Elements of Modern Algebra. United Satates of America : Brooks/Cole.

Muchlis, Ahmad \& Astuti, Pudji. 2007. Aljabar I. Jakarta : Universitas Terbuka. 